\section{Associação entre aspectos psicossociais do trabalho e qualidade de vida de mototaxistas}

\author{
Association between psychosocial aspects of work \\ and quality of life among motorcycle taxi drivers
}

\section{Asociación entre aspectos psicosociales del trabajo y calidad de vida de mototaxistas}

\begin{abstract}
This study aimed to evaluate the quality of life of motorcycle taxi drivers and the association with psychosocial characteristics of their work. This was a cross-sectional epidemiological study with a sample of 400 motorcycle taxi drivers in Jequié, Bahia State, Brazil. The study used a form containing demographic and socioeconomic data, WHO Quality of Life-Bref Questionnaire (WHOQOL-Bref), and the Job Content Questionnaire (JCQ). Motorcycle taxi drivers with greater decision-making control over their work showed better self-rated quality of life in the psychological domain; those with high psychological demands presented better self-rated quality of life in the social relations and environmental domains; those with high strain and active work showed better self-rated quality of life in the social and environmental domains. The psychosocial work environment and especially decisionmaking autonomy were thus important determinants of self-rated quality of life in this group of motorcycle taxi drivers.
\end{abstract}

Occupational Diseases; Working Conditions; Occupational Health; Quality of Life
Jules Ramon Brito Teixeira ${ }^{1}$

Eduardo Nagib Boery 1,2

Cezar Augusto Casotti 1

Tânia Maria de Araújo 3,4

Rafael Pereira 1

Ícaro José Santos Ribeiro 1,5

Marcela Andrade Rios 1,6

Camila Rego Amorim 1

Ramon Missias Moreira 1

Rita Narriman Silva de Oliveira Boery 1

Zenilda Nogueira Sales 1

\section{Resumo}

Este estudo objetivou avaliar a qualidade de vida de mototaxistas e sua relação com os aspectos psicossociais do trabalho. Estudo epidemiológico, transversal, realizado com 400 mototaxistas do Município de Jequié, Bahia, Brasil. Utilizou-se um formulário contendo dados sociodemográficos, $o$ WHO Quality of Life-Bref Questionnaire (WHOQOL-Bref) e o Job Content Questionnaire (JCQ). Os resultados evidenciaram que mototaxistas com alto controle sobre o trabalho apresentaram melhor percepção de qualidade de vida no domínio psicológico; os que possuem alta demanda psicológica apresentaram melhor percepção de qualidade de vida nos domínios relações sociais $e$ meio ambiente; aqueles com alta exigência e com trabalho ativo apresentaram melhor percepção de qualidade de vida nos domínios relações sociais e meio ambiente. Assim, o ambiente psicossocial do trabalho, es especialmente, o controle sobre o trabalho, são importantes determinantes da percepção da qualidade de vida dos mototaxistas.

Doenças Profissionais; Condições de Trabalho; Saúde do Trabalhador; Qualidade de Vida 


\section{Introdução}

A qualidade de vida dos trabalhadores tem sido amplamente discutida na atualidade e sua avaliação pode subsidiar medidas de promoção e educação em saúde 1 . O mototaxismo é uma atividade laboral que surgiu em bases informais, cujos profissionais se submetem a condições diversas para aumentar sua produtividade e lucratividade, expondo-se a múltiplos agravos e vulnerabilizando seu processo saúde/doença, podendo interferir negativamente na sua qualidade de vida 2,3 .

Nesse contexto, a globalização tem influenciado sobremaneira a constituição do novo modelo socioeconômico, acarretando mudanças estruturais decorrentes das práticas capitalistas, resultando numa reestruturação do mercado de trabalho, do emprego e da força de trabalho, a qual deve adaptar-se a esse novo mundo ${ }^{4}$. $\mathrm{O}$ processo de desenvolvimento urbano brasileiro ocasionou mudanças negativas nas relações de mercado e de organização do processo de trabalho, gerando desemprego e impulsionando as populações à crescente procura por atividades laborais informais para garantir sua sobrevivência e sustento de suas famílias 5 .

No sistema de transporte público não foi diferente, surgindo, entre as atividades laborais informais, o mototaxismo, que é um meio de transporte ágil, eficiente, de baixo custo para o trabalhador e para o usuário do serviço, contudo, nem sempre seguro. Trata-se de um serviço alternativo de meio de transporte e para alguns trabalhadores a única oportunidade de trabalho 6 .

No Brasil, a Lei Federal no 12.009, de 29 de julho de 2009, regulamentou o exercício dos mototaxistas como profissionais que transportam passageiros 7. A Resolução no 410, de 2 de agosto de 2012, do Conselho Nacional de Trânsito (CONTRAN) regulamentou a obrigatoriedade de realização de cursos especializados destinados a esses profissionais, que são ministrados pelo órgão executivo de trânsito do Estado ou do Distrito Federal, ou por órgãos, entidades e instituições por eles autorizados 8 .

Nos municípios brasileiros que regulamentaram a profissão, a legislação vigente gerou redução da precarização do trabalho dos mototaxistas, afastando-os da clandestinidade. Porém, ainda hoje, esses profissionais permanecem numa relação de informalidade, pois não possuem vínculo empregatício, direito à seguridade social ou garantias trabalhistas. Ademais, estão constantemente submetidos às más condições laborais (ritmos intensos e sobrecarga de trabalho, modificação/alteração dos horários de trabalho, violência urbana, estresse, cansaço, desgaste físico e emocional), que podem elevar os fatores condicionantes/determinantes para envolvimento em acidentes de trânsito, que se configuram como acidentes de trabalho, além de originarem distúrbios do sono, fadiga, irritabilidade, sedentarismo, entre outros problemas 6,9.

O mototaxismo caracteriza-se como uma atividade sujeita a agravos diversos, sendo estes decorrentes da exposição a acidentes por causas externas e/ou aos agentes físicos, biológicos e psicossociais. Essa exposição múltipla pode influenciar negativamente na qualidade de vida e declínio progressivo nas condições de saúde destes trabalhadores 10, interferindo nos aspectos psicossociais da sua vida pessoal e laboral bem como daqueles que com eles convivem como familiares, usuários do serviço e demais envolvidos.

Por se tratar de trabalho informal, estes trabalhadores não possuem proteção da Consolidação das Leis do Trabalho (CLT) 11 em caso de acidentes de trânsito e adoecimento. Assim, quando considerada a qualidade de vida de mototaxistas é necessário analisar o contexto no qual eles estão inseridos, incluindo análise das condições de trabalho e aspectos psicossociais envolvidos nas suas atividades laborais.

A Organização Mundial da Saúde (OMS) define qualidade de vida como a percepção que o indivíduo tem sobre sua posição na vida, no tocante à cultura e sistema de valores nos quais ele vive e em relação aos seus objetivos, expectativas, padrões e preocupações 12 . Trata-se de um conceito subjetivo, multidimensional, que envolve elementos de avaliação positivos e negativos e estabelece relação entre diferentes domínios 12,13,

Os aspectos psicossociais do trabalho referem-se à interação entre o ambiente de trabalho, conteúdo, condições organizacionais e capacidade de trabalho, necessidades, cultura e os elementos pessoais extra-trabalho, os quais podem, de acordo com a percepção e experiência do trabalhador, influenciar a saúde, satisfação e desempenho no trabalho 14. A avaliação destes aspectos psicossociais poderá ser fundamental para prevenção de doenças relacionadas ao trabalho e para promoção da saúde e melhoria da qualidade de vida desses trabalhadores 15 .

Este estudo objetivou avaliar a qualidade de vida de mototaxistas e sua relação com aspectos psicossociais do trabalho.

\section{Métodos}

Estudo epidemiológico, de corte transversal, com mototaxistas cadastrados na Associação 
dos Mototaxistas de Jequié (AMOJE), Bahia, Brasil. No cálculo amostral 16 adotou-se prevalência de qualidade de vida geral de $86,1 \% 17$ para população submetida a condições laborais semelhantes, precisão de erro de 3\%, nível de $95 \%$ de confiança e ajuste para população finita $(\mathrm{N}=$ 2.342). A amostra incluiu 420 mototaxistas, sendo acrescido adicional de perda de $20 \%$, totalizando 504 mototaxistas. Utilizou-se amostra aleatória sistemática; a seleção dos participantes foi por sorteio, considerando intervalo amostral de 5 .

Previamente ao sorteio amostral, a partir das fichas cadastrais da AMOJE, elaborou-se banco de dados constando nome, endereço laboral (pontos de mototaxi) e telefone para contato dos filiados. Posteriormente, estes dados foram organizados em ordem alfabética, numerados arabicamente e realizado o sorteio.

No período de janeiro a maio de 2013, uma equipe de pesquisadores treinada e com condutas padronizadas realizou, nos pontos de mototaxi, a coleta de dados dos profissionais sorteados. Consideraram-se até três tentativas para localizar o mototaxista; se não encontrado, este foi substituído pelo participante anterior ao intervalo amostral e, no insucesso, pelo posterior. Esgotadas as tentativas, considerou-se como perda amostral, que neste estudo correspondeu a $13,5 \%(n=68)$. Houve $7,1 \%(n=36)$ de recusa em participar do estudo. Assim, a coleta de dados foi finalizada com 400 mototaxistas.

Utilizou-se um formulário constituído por três blocos temáticos: inquérito sociodemográfico e das características laborais; inquérito sobre a qualidade de vida; e, inquérito sobre os aspectos psicossociais do trabalho.

A variável raça/cor foi autorreferida e categorizada em negros (pretos e pardos) e não-negros (brancos, amarelos e indígenas) 18.

Para mensurar a variável de desfecho, qualidade de vida, utilizou-se o WHO Quality of Life-Bref Questionnaire (WHOQOL-Bref), instrumento validado elaborado pelo World Health Organization Quality of Life Group (WHOQOL Group), composto por 26 questões 19. A primeira questão refere-se à qualidade de vida de modo geral e a segunda à satisfação com a própria saúde 12. As demais 24 questões avaliam os domínios: físico, psicológico, relações sociais e meio ambiente 19 .

As 26 questões do WHOQOL-Bref são constituídas por escalas com cinco respostas do tipo Likert, contendo escala de intensidade (nada a extremamente), capacidade (nada a completamente), frequência (nunca a sempre) e avaliação (muito insatisfeito a muito satisfeito; muito ruim a muito bom) 12,19. Para calcular os escores dos domínios utilizou-se o método proposto pelo
WHOQOL Group 12, validado no Brasil por Fleck et al. 19, obedecendo às etapas de verificação e limpeza dos dados, computação das médias das facetas e mensuração dos escores dos domínios. As questões foram pontuadas de 1 a 5; para cada faceta somaram-se os valores de cada entrevista, dividiu-se pelo número de participantes ( $\mathrm{n}=$ 400), estimando a média de cada dimensão avaliada, com posterior transformação dos escores para escala de 0 a 100 . Os valores dos itens Likert das questões 3 , 4 e 26 foram recodificados $(1=5$, $2=4,3=3,4=2,5=1$ ).

Os aspectos psicossociais do trabalho foram avaliados pelo Job Content Questionnaire (JCQ), instrumento traduzido e validado culturalmente para utilização em trabalhadores formais e informais do Brasil 20. O JCQ é instrumento derivado do modelo demanda-controle (modelo D-C) proposto por Karasek 21 e Araújo et al. 22, que avalia demandas psicológicas do trabalho (psychological demand), controle sobre o trabalho (decision latitude) e a composição entre essas dimensões.

O modelo D-C é constituído de quadrantes baseados nas respostas relativas ao controle e à demanda do JCQ. Ambos são formados por itens do tipo Likert, cujos escores variam de 1 (discordo fortemente) a 4 (concordo fortemente). Obedecendo ao método proposto por Karasek 23 , procedeu-se ao cálculo dos indicadores de controle e demanda psicológica somandose os escores obtidos em cada escala e, posteriormente, dicotomizando-os em alto e baixo, utilizando como ponto de corte as medianas de cada escala, 60 e 30 respectivamente. Após, foram construídos os quadrantes do modelo D-C: trabalho ativo (alto controle/alta demanda), alta exigência (baixo controle/alta demanda), trabalho passivo (baixo controle/baixa demanda) e baixa exigência (alto controle/baixa demanda).

Utilizou-se o software IBM SPSS, versão 20.0 (IBM Corp., Armonk, Estados Unidos), na análise dos dados. As variáveis categóricas do inquérito sociodemográfico e laboral foram descritas. Os domínios da qualidade de vida foram computados e a normalidade dos resultados testada pelo teste de normalidade de Kolmogorov-Smirnov. Para comparação de proporções da qualidade de vida entre as quatro categorias do modelo D-C aplicou-se o teste de Kruskal-Wallis, sendo aplicado o teste Mann-Whitney com correção de Bonferroni quando necessária a análise post-hoc. Utilizou-se o teste de Mann-Whitney/Wilcoxon para comparação de proporções da qualidade de vida com o controle e demanda psicológica. O nível de significância de $5 \%$ foi usado para todos os testes estatísticos. Os resultados foram apresentados em média \pm desvio-padrão. 
A pesquisa foi aprovada pelo Comitê de Ética em Pesquisa da Universidade Estadual do Sudoeste da Bahia, obedecendo à Resolução no 466/12 do Conselho Nacional de Saúde, sob parecer no 127.467 .

\section{Resultados}

Em decorrência das perdas $(13,5 \%)$ e recusas $(7,1 \%)$, foram estudados 400 mototaxistas. As perdas aconteceram pelo fato dos mototaxistas não terem sido encontrados no momento da coleta por estarem em serviço ou terem deixado de trabalhar na atividade.

Dos mototaxistas estudados 392 (98\%) eram do sexo masculino, 169 (42,2\%) estavam na faixa dos 30 aos 39 anos, média de 33,4 anos $( \pm 9,4$; mínimo = 21 e máximo = 65). Quanto à situação conjugal, 224 (56\%) eram casados/união estável. Os níveis de escolaridade predominantes foram Ensino Fundamental completo (47,5\%) e Ensino Médio completo (35\%) (Tabela 1). Para raça/cor, $221(55,2 \%)$ autodeclararam-se negros. Quanto à renda mensal, $174(43,5 \%)$ informaram receber de 3 a 4 salários mínimos mensais ( $\mathrm{R} \$ 2.034,00$ a $\mathrm{R} \$ 2.712,00)$, sendo a média de $\mathrm{R} \$ 2.380,25$ $( \pm 649,6 ;$ mínimo $=\mathrm{R} \$ 1.000,00$ e máximo $=\mathrm{R} \$$ $4.000,00)$, correspondendo à renda média mensal de 3,5 salários mínimos.

Considerando as características do trabalho, verificou-se que 346 (86,5\%) mototaxistas não possuíam outro trabalho ou ocupação, 254 $(63,5 \%)$ desenvolviam esta atividade há cinco

Tabela 1

Características sociodemográficas e laborais dos mototaxistas $(N=400)$. Jequié, Bahia, Brasil, 2013.

\begin{tabular}{|c|c|c|}
\hline Variáveis & $\mathrm{n}$ & $\%$ \\
\hline \multicolumn{3}{|l|}{ Caraterísticas sociodemográficas } \\
\hline \multicolumn{3}{|l|}{ Sexo } \\
\hline Masculino & 392 & 98,0 \\
\hline Feminino & 8 & 2,0 \\
\hline \multicolumn{3}{|l|}{ Faixa etária (anos) } \\
\hline $21-29$ & 136 & 34,0 \\
\hline $30-39$ & 169 & 42,2 \\
\hline $40-49$ & 67 & 16,8 \\
\hline 50 ou mais & 28 & 7,0 \\
\hline \multicolumn{3}{|l|}{ Situação conjugal } \\
\hline Solteiro(a) & 114 & 28,5 \\
\hline Casado(a)/União estável & 224 & 56,0 \\
\hline Divorciado(a)/Separado(a)/Desquitado(a) & 47 & 11,7 \\
\hline Viúvo(a) & 15 & 3,8 \\
\hline \multicolumn{3}{|l|}{ Escolaridade } \\
\hline Analfabeto & 16 & 4,0 \\
\hline Ensino Fundamental & 190 & 47,5 \\
\hline Ensino Médio & 140 & 35,0 \\
\hline Ensino Técnico & 36 & 9,0 \\
\hline Ensino Superior & 18 & 4,5 \\
\hline \multicolumn{3}{|l|}{ Raça/Cor } \\
\hline Negros (pretos e pardos) & 221 & 55,2 \\
\hline Não negros (brancos, amarelos e indígenas) & 123 & 30,8 \\
\hline Não sabe & 56 & 14,0 \\
\hline \multicolumn{3}{|l|}{ Renda (salários mínimos) } \\
\hline$\leq 2$ (até $\mathrm{R} \$ 1.356,00$ ) & 26 & 6,5 \\
\hline $2-3(R \$ 1.356,00$ a $R \$ 2.034,00)$ & 85 & 21,2 \\
\hline 3-4 (R\$2.034,00 a $\mathrm{R} \$ 2.712,00)$ & 174 & 43,5 \\
\hline 4 ou mais ( $\mathrm{R} \$ 2.712,00$ ou mais) & 115 & 28,8 \\
\hline
\end{tabular}

(continua) 
Tabela 1 (continuação)

\begin{tabular}{|c|c|c|}
\hline Variáveis & $\mathrm{n}$ & $\%$ \\
\hline \multicolumn{3}{|c|}{ Características laborais } \\
\hline \multicolumn{3}{|c|}{ Outro trabalho ou ocupação } \\
\hline Sim & 54 & 13,5 \\
\hline Não & 346 & 86,5 \\
\hline \multicolumn{3}{|c|}{ Tempo de trabalho como mototaxista (anos) } \\
\hline$<5$ & 146 & 36,5 \\
\hline 5 ou mais & 254 & 63,5 \\
\hline \multicolumn{3}{|c|}{ Contribui com a Previdência Social (INSS) } \\
\hline $\operatorname{Sim}$ & 54 & 13,5 \\
\hline Não & 346 & 86,5 \\
\hline \multicolumn{3}{|c|}{ Quantidade de dias de trabalho por semana } \\
\hline Até 5 & 65 & 16,2 \\
\hline $6-7$ & 335 & 83,8 \\
\hline \multicolumn{3}{|c|}{ Quantidade de horas de trabalho por dia } \\
\hline Até 8 & 56 & 14,0 \\
\hline 8 ou mais & 344 & 86,0 \\
\hline \multicolumn{3}{|c|}{ Turnos de trabalho por dia } \\
\hline 1 & 87 & 21,8 \\
\hline 2 ou mais & 313 & 78,2 \\
\hline \multicolumn{3}{|c|}{ Local de descanso no trabalho } \\
\hline Sim & 102 & 25,5 \\
\hline Não & 298 & 74,5 \\
\hline \multicolumn{3}{|c|}{ Sanitário no trabalho } \\
\hline $\operatorname{Sim}$ & 27 & 6,8 \\
\hline Não & 373 & 93,2 \\
\hline \multicolumn{3}{|c|}{ Exposição ao calor } \\
\hline Sim & 379 & 94,8 \\
\hline Não & 21 & 5,2 \\
\hline \multicolumn{3}{|c|}{ Exposição ao frio } \\
\hline Sim & 235 & 58,8 \\
\hline Não & 165 & 41,2 \\
\hline \multicolumn{3}{|c|}{ Exposição a ruídos excessivos } \\
\hline Sim & 374 & 93,5 \\
\hline Não & 26 & 6,5 \\
\hline \multicolumn{3}{|c|}{ Exposição à poeira/ao pó } \\
\hline Sim & 375 & 93,8 \\
\hline Não & 25 & 6,2 \\
\hline \multicolumn{3}{|c|}{ Exposição a gases/fumaça/vapores } \\
\hline Sim & 363 & 90,8 \\
\hline Não & 37 & 9,2 \\
\hline
\end{tabular}

anos ou mais, 346 (86,5\%) não contribuíam com a Previdência Social (INSS), $335(83,8 \%)$ trabalhavam de 6 a 7 dias/semana, 344 (86\%) tinham carga horária diária de trabalho de 8 ou mais horas, sendo a média de 11,7 horas/dia $( \pm 2,6$; mínimo = 6 e máximo $=16$ ). Verificou-se que 313 $(78,2 \%)$ trabalhavam diariamente dois turnos ou mais, 298 (74,5\%) não possuíam local de descanso, 373 (93,2\%) não dispunham de sanitário no trabalho, $379(94,8 \%)$ ficavam expostos ao calor, $235(58,8 \%)$ ao frio, $374(93,5 \%)$ a ruídos excessivos no trânsito, 375 (93,8\%) ao contato e/ ou inalação de poeira/pó de diversas origens, e, $363(90,8 \%)$ ao contato e/ou inalação de gases, fumaça e vapores.

A Tabela 2 apresenta médias, desvios-padrão e valores máximo e mínimo dos domínios da qualidade de vida. O domínio da qualidade de 
Média, desvio-padrão (DP), mínimo e máximo dos domínios da qualidade de vida dos mototaxistas ( $N=400)$. Jequié, Bahia, Brasil, 2013

\begin{tabular}{lcccc}
\hline Domínios do WHOQOL-Bref & Média & DP & Mínimo & Máximo \\
\hline Físico & 42,4 & 10,4 & 14,3 & 75,0 \\
Psicológico & 43,1 & 9,3 & 16,7 & 70,8 \\
Relações sociais & 61,6 & 13,9 & 16,7 & 91,7 \\
Meio ambiente & 28,5 & 7,7 & 9,4 & 53,1 \\
Índice de qualidade de vida geral & 27,7 & 17,6 & 0,0 & 87,5 \\
\hline
\end{tabular}

WHOQOL-Bref: World Health Organization Quality of Life-Bref Questionnaire.

vida que apresentou média mais elevada foi relações sociais, seguida do psicológico; as menores médias foram observadas para qualidade de vida geral e meio ambiente.

Considerando os aspectos psicossociais do trabalho dos mototaxistas, verificou-se que 214 $(53,5 \%)$ possuíam baixo controle sobre o trabalho e 186 (46,5\%) alto controle; 218 (54,5\%) baixa demanda psicológica e $182(45,5 \%)$ alta demanda.

A comparação da percepção de qualidade de vida entre os grupos controle sobre o trabalho (Tabela 3) permitiu identificar diferenças significativas entre os grupos no domínio psicológico, sendo constatado que indivíduos com alto controle apresentaram melhor percepção de qualidade de vida no domínio psicológico. Não houve diferenças significativas para os demais domínios avaliados.

A comparação da percepção de qualidade de vida entre os grupos por níveis de demanda psicológica (Tabela 4) evidenciou diferença significativa para os domínios relações sociais e meio ambiente; os indivíduos com alta demanda psicológica no trabalho apresentaram melhor percepção de qualidade de vida nesses domínios.

Segundo o modelo D-C, 110 (27,5\%) mototaxistas foram caracterizados como tendo trabalho passivo, 108 (27\%) trabalho de baixa exigência, 104 (26\%) trabalho de alta exigência e 78 (19,5\%) trabalho ativo.

Considerando os grupos do modelo D-C, foram observadas diferenças estatisticamente significantes entre os grupos para os domínios relações sociais e meio ambiente (Tabela 5). Na análise post-hoc constatou-se que mototaxistas em situação de trabalho ativo (alto controle e alta demanda psicológica) apresentaram maiores médias de qualidade de vida nos domínios relações sociais $(65,2)$ e meio ambiente $(30,2)$, seguidos dos mototaxistas em situação de alta exigência (63,9 e 29,6 respectivamente).

\section{Discussão}

A atividade profissional do mototaxista foi recentemente regulamentada e a literatura científica nacional e internacional carece de estudos, evidenciando a invisibilidade desta categoria profissional, o que dificultou, em parte, a comparação dos achados deste estudo 2 .

Destaca-se que não há estimativas oficiais do número de mototaxistas no Município de Jequié. Por se tratar de trabalho autônomo, o número destes trabalhadores está sujeito a constantes flutuações. Os mototaxistas de Jequié constituíram a AMOJE para melhor organizar e lutar para regulamentação da profissão diante dos poderes Legislativo e Executivo. Mesmo sem a regulamentação, o setor de transportes da Prefeitura Municipal delimitou estacionamentos privativos para os pontos cadastrados na AMOJE em locais estratégicos de maior circulação de pessoas nos diversos bairros do município, porém, a estrutura física desses pontos, a céu aberto, serve apenas para acomodação das motocicletas e aglomeração dos mototaxistas.

O exercício do mototaxismo em Jequié, diferentemente de outros municípios do Brasil 24,25,26,27, ainda não está delimitado por exigências legais, dificultando o controle da expansão do número de trabalhadores, diagnóstico situacional das condições laborais e devida fiscalização por órgãos competentes.

Considerando as características sociodemográficas dos mototaxistas estudados, identificaram-se semelhanças com outros estudos $5,6,23,28,29,30$. Geralmente são profissionais jovens e adultos jovens, do sexo masculino, negros, solteiros ou que convivem em união estável, com baixo nível de escolaridade.

Os jovens e aqueles com faixas etárias mais elevadas encontraram no mototaxismo uma opção laboral lucrativa, cuja opção pode ter se dado em decorrência do baixo grau de escolaridade, 
Tabela 3

Comparação dos domínios da qualidade de vida com os grupos estratificados pelo controle sobre o trabalho dos mototaxistas ( $N=400)$. Jequié, Bahia, Brasil, 2013.

\begin{tabular}{llc}
\hline Domínios do WHOQOL-Bref/Controle sobre o trabalho & Média \pm DP & Valor de p \\
\hline Físico & & 0,939 \\
$\quad$ Baixo controle & $42,4 \pm 10,8$ & 0,040 * \\
$\quad$ Alto controle & $42,3 \pm 10,0$ & \\
Psicológico & & \\
$\quad$ Baixo controle & $42,2 \pm 9,7$ & 0,785 \\
$\quad$ Alto controle & $44,2 \pm 8,8$ & \\
Relações sociais & & 0,736 \\
$\quad$ Baixo controle & $61,8 \pm 13,3$ & \\
$\quad$ Alto controle & $61,3 \pm 14,5$ & \\
Meio ambiente & & 0,206 \\
$\quad$ Baixo controle & $28,6 \pm 7,8$ & \\
Alto controle & $28,4 \pm 7,7$ & \\
Índice de qualidade de vida geral & & \\
$\quad$ Baixo controle & $28,6 \pm 17,6$ & \\
Alto controle & $26,7 \pm 17,7$ & \\
\hline
\end{tabular}

DP: desvio-padrão; WHOQOL-Bref: World Health Organization Quality of Life-Bref Questionnaire.

* Diferença estatisticamente significante $(p<0,05)$.

Tabela 4

Comparação dos domínios da qualidade de vida com os grupos estratificados pela demanda psicológica dos mototaxistas ( $N=400)$. Jequié, Bahia, Brasil, 2013.

\begin{tabular}{lcc}
\hline $\begin{array}{l}\text { Domínios do WHOQOL-Bref/ } \\
\text { Demanda psicológica do trabalho }\end{array}$ & Média \pm DP & Valor de p \\
\hline Físico & & 0,625 \\
$\quad$ Baixa demanda & $42,0 \pm 10,7$ & \\
$\quad$ Alta demanda & $42,9 \pm 10,1$ & 0,671 \\
Psicológico & $43,3 \pm 9,1$ & \\
Baixa demanda & $42,9 \pm 9,5$ & 0,000 * \\
Alta demanda & & 0,001 * \\
Relações sociais & $59,1 \pm 13,2$ & \\
Baixa demanda & $64,5 \pm 14,2$ & 0,957 \\
Alta demanda & & \\
Meio ambiente & $27,4 \pm 7,9$ & \\
Baixa demanda & $29,9 \pm 7,3$ & \\
Alta demanda & & \\
Índice de qualidade de vida geral & $27,8 \pm 17,5$ & \\
Baixa demanda & $27,6 \pm 17,8$ & \\
Alta demanda &
\end{tabular}

DP: desvio-padrão; WHOQOL-Bref: World Health Organization Quality of Life-Bref Questionnaire.

* Diferença estatisticamente significante $(p<0,05)$. 
Comparação dos domínios da qualidade de vidacom as categorias estratificadas pelo modelo demanda-controle (modelo D-C) dos mototaxistas ( $\mathrm{N}=$ 400). Jequié, Bahia, Brasil, 2013.

\begin{tabular}{|c|c|c|}
\hline $\begin{array}{l}\text { Domínios do WHOQOL-Bref/ } \\
\text { Demanda/Controle }\end{array}$ & Média \pm DP & Valor de $\mathrm{p}$ \\
\hline Físico & & 0,830 \\
\hline Trabalho passivo & $41,6 \pm 10,6$ & \\
\hline Baixa exigência & $42,4 \pm 10,7$ & \\
\hline Alta exigência & $43,3 \pm 10,9$ & \\
\hline Trabalho ativo & $42,2 \pm 9,0$ & \\
\hline Psicológico & & 0,111 \\
\hline Trabalho passivo & $41,8 \pm 9,3$ & \\
\hline Baixa exigência & $44,9 \pm 8,7$ & \\
\hline Alta exigência & $42,6 \pm 10,0$ & \\
\hline Trabalho ativo & $43,2 \pm 8,8$ & \\
\hline Relações sociais & & $0,000 *$ \\
\hline Trabalho passivo & $59,7 \pm 11,9$ & \\
\hline Baixa exigência & $58,6 \pm 14,4$ & \\
\hline Alta exigência ** & $63,9 \pm 14,4$ ** & \\
\hline 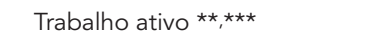 & 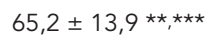 & \\
\hline Meio ambiente & & 0,005 * \\
\hline Trabalho passivo & $27,6 \pm 8,0$ & \\
\hline Baixa exigência & $27,1 \pm 7,8$ & \\
\hline Alta exigência & $29,6 \pm 7,5$ & \\
\hline Trabalho ativo ** & $30,2 \pm 7,1 * \star$ & \\
\hline Índice de qualidade de vida geral & & 0,650 \\
\hline Trabalho passivo & $28,8 \pm 17,8$ & \\
\hline Baixa exigência & $26,9 \pm 17,2$ & \\
\hline Alta exigência & $26,4 \pm 18,5$ & \\
\hline Trabalho ativo & $26,4 \pm 18,5$ & \\
\hline
\end{tabular}

DP: desvio-padrão; WHOQOL-Bref: World Health Organization Quality of Life-Bref Questionnaire.

* Diferença estatisticamente significante $(p<0,05)$.

** Significativamente diferente da condição baixa exigência $(p<0,05)$;

$\star \star \star$ Significativamente diferente da condição trabalho passivo $(p<0,05)$.

que gerou dificuldade de inserção no atual mercado formal de trabalho 2 .

Corroborando outro estudo 2 , frequentemente os mototaxistas não possuem outro tipo de trabalho ou ocupação, o que pode ser justificado pelo fato de os mesmos se submeterem a extensas jornadas e cargas horárias de trabalho, perfazendo mais de oito horas diárias e em torno de seis a sete dias de trabalho por semana. A elevada carga horária associada às condições insalubres de trabalho, seja quando estão transportando os passageiros ou quando os aguardam nos pontos de mototaxi, podem comprometer a saúde, bem como a qualidade de vida desses profissionais.

Condições de trabalho precárias podem agravar o estresse laboral e afetar a qualidade de vida de mototaxistas por estarem expostos a ruídos, fumaças e frio/calor excessivos, riscos de acidente e tensão interpessoal. Destaca-se ainda que trabalho em turnos sequenciais configurase como agente estressor, capaz de impactar na qualidade de vida, alterando o ritmo neurofisiológico do organismo, elevando a temperatura sanguínea, taxa metabólica, níveis glicêmicos séricos, eficiência mental e motivação para o trabalho 31 .

A sobrecarga de trabalho pode influenciar a qualidade de vida dos mototaxistas. Essa sobrecarga pode ser de ordem quantitativa (muitas tarefas a fazer) e qualitativa (trabalho difícil). A primeira em decorrência do excessivo número de corridas para aumento da produtividade e do 
lucro, e a segunda pela desordem física e psicossocial concernentes ao desgaste laboral e pela exposição aos fatores externos. Daí pode advir sintomas de estresse associados a estas situações, como autoestima diminuída, baixa motivação para o trabalho e escapismo alcoólico 31 .

A sobrecarga, juntamente com o trabalho repetitivo, a monotonia e rotina diárias, o ambiente de trabalho pouco estimulante têm sido associados ao maior risco de adoecer e, consequentemente, podem afetar negativamente a qualidade de vida dos mototaxistas. Assim, deve haver equilíbrio entre o indivíduo, o ambiente e a satisfação no trabalho, pois a interação negativa entre as características psicossociais do indivíduo e as condições ambientais do seu trabalho pode resultar em ansiedade, depressão, insatisfação com o trabalho e, até mesmo, doenças fisiológicas.

Além disso, o risco à integridade física, característico da atividade do mototaxismo, pode provocar estresse ocupacional, uma vez que a possibilidade de acidentes graves de trânsito está sempre presente no cotidiano laboral. Medidas preventivas ou paliativas como o uso de equipamentos de proteção e segurança (vestuário adequado, capacete, colete, botas e dispositivos infláveis para acionamento em casos de acidentes), bem como capacitação e treinamento para atuar na profissão, são ações que podem minimizar os riscos e seus efeitos estressores.

O CONTRAN estabelece cursos específicos para o exercício profissional dos mototaxistas $6,8,32$. Os cursos visam capacitar o mototaxista a realizar adequadamente o transporte de passageiros, incluindo orientações para minimizar as circunstâncias de vulnerabilidade causada pela motocicleta e pela exposição do sujeito ao contexto urbano e abordagem teórica sobre transporte de pessoas e aula prática de pilotagem profissional 8 .

A qualidade de vida dos mototaxistas está relacionada ao cotidiano desses profissionais, que é marcado pelo desgaste físico, o qual tende a diminuir os seus reflexos, tornando-os mais vulneráveis a sofrerem acidentes de trânsito 2 . Na maioria das vezes os mototaxistas permanecem em atitudes posturais forçadas em função da estrutura da motocicleta 33 , os pontos de mototaxi não possuem local para descanso ou realização de refeições e sanitário para satisfação das necessidades fisiológicas, elementos indispensáveis para o mínimo de conforto no ambiente laboral. Portanto, os mototaxistas ficam sujeitos à alternância das condições climáticas, além da exposição à poeira, ruídos, fumaça/gases e à violência urbana e do trânsito. Todos esses fatores somados intensificam as situações de exposição ocu- pacional desses profissionais e implicam adoção de posturas e comportamentos involuntários em função das exigências do trabalho, colocando em risco a saúde e a vida dos mototaxistas.

Sabe-se que trabalhadores que realizam suas atividades "a céu aberto" estão expostos às temperaturas altas/baixas, ventos e poluição ambiental consequente da exposição ao monóxido de carbono (CO), dióxido de enxofre $\left(\mathrm{SO}_{2}\right)$, ozônio $\left(\mathrm{O}_{3}\right)$, óxidos de nitrogênio $\left(\mathrm{NO}_{\mathrm{x}}\right)$ como o dióxido de nitrogênio $\left(\mathrm{NO}_{2}\right)$ e óxido nítrico (NO) ${ }^{34,35}$. Os mototaxistas além de estarem expostos diretamente à poluição, que pode resultar em agravos diversos à sua saúde, estão expostos aos riscos decorrentes do trabalho em si, como acidentes de trabalho, risco de apresentarem alterações psicológicas e assaltos 24,36.

Segundo estudo com 267 mototaxistas do Município de Feira de Santana, Bahia, Brasil 2, a ocorrência de acidentes de trabalho apresentou associação estatisticamente significativa com a presença de fadiga em membros inferiores e queixa musculoesquelética. O estudo apontou que esses resultados podem ser decorrentes das precárias condições de trabalho às quais os mototaxistas estão submetidos, porquanto os pontos de mototaxi não possuem local adequado para descanso e/ou pausas; dessa forma, eles não dispõem de espaço com infraestrutura necessária para que possam recompor os esforços posturais peculiares à sua atividade laboral nos períodos em que não estão transportando os usuários do serviço.

Os mototaxistas são trabalhadores autônomos, exercem sua profissão em bases informais e a maioria não contribui com o INSS. Quando esses trabalhadores sofrem algum tipo de acidente de trabalho, ficam desprotegidos dos benefícios concedidos pela legislação trabalhista 2,24 . A falta de registro em Carteira de Trabalho e INSS, que constitui o vínculo informal e/ou inexistência de vínculo trabalhista, impede que o mototaxista possa usufruir do direito ao auxílioacidente garantido pela legislação aos trabalhadores contribuintes que sofreram acidentes de trabalho e ficaram com sequelas que reduzam sua capacidade de trabalho, gerando consequências negativas à sua qualidade de vida. Afora isso, a legislação ainda prevê outros benefícios, que também estão relacionados à melhoria da qualidade de vida e condições laborais desses profissionais, quais sejam, direito a férias, décimo terceiro salário, aposentadoria, licença remunerada por doença e regulação da jornada e turno de trabalho 6 .

Com relação à remuneração, mesmo após considerar os gastos que o exercício da profissão implicava (manutenção, combustível, deprecia- 
ção elevada do veículo, equipamento de proteção individual, pagamento do ponto de mototaxi e filiação à associação), os achados obtidos corroboram outros estudos 2,6,26,36 que apontam a profissão como uma atividade rentável e financeiramente relevante para a família, sendo alternativa de trabalho com boa remuneração, mesmo na informalidade $2,5,6,37$. Com condições financeiras comparativamente melhores do que os trabalhadores em geral, que recebem salário mínimo, os mototaxistas têm possibilidade de adquirir os meios necessários para melhoria da sua qualidade de vida de acordo com a sua percepção, anseios e conquistas do dia a dia. As condições laborais desfavoráveis, às quais estão submetidos, são consideradas desafios na obtenção dessas conquistas, sendo, frequentemente, negligenciadas ou minimizadas em função do retorno financeiro que a atividade oferece, especialmente se considerarmos que se trata de um grupo de baixa competitividade no mercado de trabalho. Ou seja, o mototaxismo, além de permitir a inserção no mercado laboral, permite remuneração maior do que o trabalho formal de carteira assinada na situação predominante no Brasil.

Registrou-se média baixa no indicador geral de qualidade de vida que contrasta, por outro lado, com média elevada no domínio de relações sociais. Estes achados evidenciam comprometimento de algumas dimensões da qualidade de vida (que reflete no indicador global), mas destaca uma dimensão específica como positiva nesta atividade laboral: a ampla rede de contatos sociais.

Na avaliação específica da qualidade de vida dos mototaxistas estudados, os domínios físico e meio ambiente foram os mais afetados. Não foram encontrados estudos envolvendo mototaxistas, ou outros motociclistas profissionais, aparentemente saudáveis para realizar análise comparativa dos dados. Os estudos publicados avaliam a qualidade de vida de motociclistas acidentados ou com alguma espécie de lesão decorrente desses acidentes e, sendo assim, infere-se que, ao responder às facetas do WHOQOL-Bref, os motociclistas podem apresentar viés recordatório em decorrência do trauma ou da condição de vida atual após os acidentes.

O domínio físico avalia as facetas da dor e desconforto; energia e fadiga; sono e repouso; mobilidade; atividades da vida cotidiana; dependência de medicação ou de tratamentos; e, capacidade de trabalho. O domínio meio ambiente avalia a segurança física e proteção; ambiente no lar; recursos financeiros; cuidados de saúde e sociais; oportunidades de adquirir novas informações e habilidades; participação e oportunidades de recreação/lazer; ambiente físico (poluição/ ruído/trânsito/clima); e, transporte 12,13.

Considerando as condições laborais dos mototaxistas, evidenciaram-se as razões para um maior impacto sobre estes domínios, pois o desgaste físico proveniente da rotina laboral pode gerar dor física, estresse laboral, fadiga, perda de sono ou sono excessivo, e, inclusive diminuir a capacidade para o trabalho e ocasionar acidentes de trânsito. Além disso, tornam-se vulneráveis em sua relação com o meio ambiente, visto que a extensa jornada de trabalho, a exposição aos ruídos excessivos, poluição urbana, alternância climática (oscilando entre elevadas ou baixas temperaturas, chuva), violência do trânsito, dentre outros fatores, colocam em risco sua saúde e segurança, desestimulando-os a praticar atividades físicas (por falta de tempo ou por esgotamento físico/mental), podendo aumentar a probabilidade de adoecer e dificultar as relações sociais e familiares.

Quando analisada a qualidade de vida estratificada pelos grupos do controle sobre o trabalho, o alto controle impactou na melhor percepção da qualidade de vida no domínio psicológico do WHOQOL-Bref. As facetas desse domínio avaliam a frequência de sentimentos positivos e negativos; capacidade de pensar, aprender, memória e concentração; autoestima; satisfação com a imagem corporal e aparência, e, espiritualidade/ religiosidade/crenças pessoais 12,19 .

O controle sobre o trabalho refere-se ao uso de habilidades, ou seja, à capacidade de aprender coisas novas, variabilidade das tarefas, criatividade e desenvolvimento de habilidades especiais. Envolve autoridade decisória, que é a habilidade individual para tomar decisões sobre o próprio trabalho, influência do grupo de trabalho e influência na política gerencial do serviço 22,23 .

Avaliando a autopercepção dos mototaxistas quanto ao domínio psicológico da sua qualidade de vida e constatando a sua relação com o alto controle sobre o trabalho, infere-se que esse controle pode aumentar a concentração na condução da motocicleta, na execução das demais tarefas e estimulá-los a aprender como lidar com a rotina estressante decorrente da repetitividade diária do serviço, sobrecarga de trabalho, pressão de tempo e produtividade, e, até mesmo, desenvolver habilidades e criatividade para desempenhar seu trabalho. Assim, o alto controle sobre as tarefas pode minimizar os efeitos nocivos das características do trabalho para o domínio psicológico da qualidade de vida dos mototaxistas, reduzindo a presença ou frequência de sentimentos negativos no seu dia a dia, a ansiedade, depressão e estresse laboral, diminuindo a probabilidade de adoecer, que são 
questões avaliadas nesta dimensão da qualidade de vida.

Considerando a qualidade de vida segundo demanda psicológica, verificou-se que os mototaxistas com maior demanda psicológica no trabalho apresentaram melhor percepção da qualidade de vida nos domínios relações sociais e meio ambiente.

A demanda psicológica do trabalho 22, no contexto dos mototaxistas, se refere às exigências psicológicas que esses profissionais enfrentam no trabalho, relacionando-se com pressão do tempo, nível de concentração requerida ao pilotar, interrupção das tarefas e necessidade de esperar por sua preferência pela próxima corrida nos pontos de mototaxi, pois geralmente esses profissionais estabelecem uma ordem na sequência de quem será o próximo a transportar o passageiro que solicitar o serviço.

A interação com o meio ambiente e convívio social no trabalho, mesmo em situações de alta demanda psicológica, diminuem esses estressores decorrentes da rotina diária, gerando menor impacto sobre a qualidade de vida desses profissionais. Nessa perspectiva, os mototaxistas que desenvolviam suas atividades com necessidade de maior nível de atenção e concentração, mesmo sofrendo pressão de tempo, tiveram uma melhor percepção da qualidade de vida. Esses achados são discordantes de estudos que avaliaram demandas psicológicas em grupos de trabalhadores e observaram impactos negativos de altas demandas na saúde 21,22,23,38. A análise das especificidades do trabalho de mototaxistas pode auxiliar na compreensão desses resultados aparentemente inesperados.

Médias mais elevadas de qualidade de vida nos domínios de relações sociais e meio ambiente em alta demanda psicológica correspondem ao tipo de trabalho articulado aos padrões desejáveis de produtividade, implicando maior fluxo de passageiros, de contatos sociais e maior retorno financeiro. A busca permanente de produção ("corridas" contínuas), mesmo ao custo de ritmo acelerado de trabalho, parece ser algo desejado, envolvendo orgulho profissional e satisfação. Atua, assim, como marcador de sucesso e reconhecimento: quem é muito requisitado, possui amplos contatos sociais; ao mesmo tempo isto garante maior remuneração. Registra-se ainda que a população estudada era relativamente jovem $(76,2 \%$ tinham menos de 40 anos) e, como trata-se de uma ocupação recente, é plausível considerar a possibilidade de que o tempo de exposição a situações de elevadas demandas ainda não foi suficiente para produzir os efeitos deletérios das altas demandas observados em outros estudos, especialmente considerando o fato de que o trabalho sob elevada demanda configura maior produtividade, podendo ser este um modulador importante na relação observada com a qualidade de vida.

Deve-se considerar também que este estudo é transversal, pontual no tempo; portanto, cabe analisar a hipótese de não inclusão de mototaxistas que podem ter apresentado efeitos negativos na qualidade de vida decorrente do trabalho em altas demandas e por isto abandonaram a profissão. O efeito trabalhador sadio atua para selecionar e manter em atividade os trabalhadores mais saudáveis 22 .

Com relação aos aspectos psicossociais do mototaxismo, observou-se que os mototaxistas na situação de trabalho ativo (alto controle/alta demanda) possuíam maiores médias de qualidade de vida nos domínios relações sociais e meio ambiente, seguidos por aqueles em alta exigência. Tanto na situação de alta exigência quando em trabalho ativo são vivenciadas elevadas demandas psicológicas. Assim, aspectos relacionados às altas demandas em mototaxistas, discutidos acima, podem ser evocados também para a compreensão desses achados, ressaltando-se que alto controle parece atuar positivamente na qualidade de vida, uma vez que foram observadas médias maiores em alto controle (trabalho ativo) quando comparado ao baixo controle (alta exigência).

O efeito positivo do controle é destacado em estudos que apontam que os reforços provenientes do alto controle sobre o trabalho podem ter a capacidade de bloquear ou minimizar as consequências negativas advindas da alta demanda psicológica 22,39, sendo esta uma provável explicação para a melhor percepção da qualidade de vida dos mototaxistas em trabalho ativo nos domínios de relações sociais e meio ambiente.

O domínio das relações sociais avalia as relações pessoais, suporte/apoio social e a atividade sexual 12,19. Os dados mostram que no trabalho os mototaxistas estabelecem vínculos relacionais de amizade e parceria durante o transporte dos passageiros e com os colegas de trabalho nos pontos de mototaxi e, dessa maneira, sociabilizam-se e buscam mecanismos para diminuir as diversas sobrecargas que o trabalho traz para suas vidas. A maioria desses pontos de mototaxi localiza-se em ambientes de grande concentração urbana e onde o fluxo de pessoas é mais intenso, favorecendo o contato e interação com o meio ambiente à sua volta.

Apesar do dado observado com relação ao trabalho em alta exigência, cabe mencionar que outras pesquisas evidenciaram que trabalhadores com alta exigência apresentam as reações mais adversas à saúde, produtividade e satisfa- 
ção 22,39,40,41. Portanto, o achado de situação favorável à qualidade de vida em trabalho de alta exigência deve ser analisado cuidadosamente em função das características específicas do tipo de trabalho analisado. Estudos futuros devem explorar os aspectos percebidos como demandas psicológicas nesse grupo e que relações estabelece com recompensas no trabalho.

Deve-se considerar que estudos transversais apresentam limitações por retratarem uma situação epidemiológica de um momento específico da saúde. Portanto, avaliam apenas os trabalhadores saudáveis e excluem aqueles que, por razões de saúde, não estavam trabalhando no momento da coleta de dados.

\section{Conclusões}

Os mototaxistas de Jequié tiveram maior média de pontuação na avaliação global da qualidade de vida nos domínios psicológico e relações sociais.

Quando comparada a qualidade de vida com o controle sobre o trabalho foi constatado que os mototaxistas com alto controle apresentaram melhor percepção de qualidade de vida no domínio psicológico; quando associada à demanda psicológica do trabalho à qualidade de vida verificou-se que os mototaxistas com alta demanda apresentaram melhor percepção de qualidade de vida nos domínios relações sociais e meio ambiente.

Quanto à relação do modelo D-C e qualidade de vida, constatou-se que os trabalhadores em trabalho ativo (alto controle/alta demanda) apresentaram melhor percepção de qualidade de vida nos domínios relações sociais e meio ambiente, seguidos pelos mototaxistas em alta exigência (baixo controle/alta demanda). Assim, evidenciou-se que o ambiente psicossocial do trabalho e, especialmente o controle sobre o trabalho, é importante determinante da percepção de qualidade de vida dos mototaxistas.

Os aspectos psicossociais do trabalho e a qualidade de vida dos mototaxistas merecem maior atenção dos profissionais de saúde, pesquisadores e gestores dos diversos órgãos de segurança, saúde do trabalhador e do trânsito nas diferentes esferas de governo, no sentido de implementar estratégias e ações que visem à promoção da saúde e melhoria da qualidade de vida desses trabalhadores.

\section{Resumen}

Este estudio tuvo como objetivo evaluar la calidad de vida de los mototaxistas y su relación con los aspectos psicosociales del trabajo. Estudio epidemiológico, transversal, realizado con 400 mototaxistas del municipio de Jequié, Bahía, Brasil. Se utilizó un formulario con datos sociodemográficos, el WHO Quality of LifeBref Questionnaire (WHOQOL-Bref) y el Job Content Questionnaire (JCQ). Los resultados evidenciaron que los mototaxistas con un alto control de trabajo presentaron mejor percepción de la calidad de vida en el dominio psicológico; aquellos con una alta demanda psicológica tuvieron mejor percepción de calidad de vida en los dominios de relaciones sociales y el medio ambiente; aquellos con alta exigencia y trabajo activo mostraron mejor percepción de la calidad de vida en los dominios de relaciones sociales y medio ambiente. Así, el ambiente psicosocial del trabajo y, especialmente, el control sobre el trabajo son determinantes importantes para la percepción de la calidad de vida de los mototaxistas.

Enfermedades Profesionales; Condiciones de Trabajo; Salud Laboral; Calidad de Vida

\section{Colaboradores}

J. R. B. Teixeira, E. N. Boery, C. A. Casotti e R. M. Moreira participaram da concepção do projeto, coleta, análise e interpretação dos dados; redação e revisão crítica do artigo e aprovação final da versão a ser publicada. T. M. Araújo, R. Pereira, I. J. S. Ribeiro, C. R. Amorim, R. N. S. O. Boery e Z. N. Sales colaboraram na concepção do projeto, análise e interpretação dos dados; redação e revisão crítica do artigo e aprovação final da versão a ser publicada. M. A. Rios contribuiu na análise e interpretação dos dados e na redação e revisão crítica do artigo.

\section{Agradecimentos}

À FAPESB pela concessão de bolsa de mestrado acadêmico. 


\section{Referências}

1. Buss PM. Promoção da saúde e qualidade de vida. Ciênc Saúde Coletiva 2000; 5:163-77.

2. Amorim CR, Araújo EM, Araújo TM, Oliveira NF Acidentes de trabalho com mototaxistas. Rev Bras Epidemiol 2012; 15:25-37.

3. Oliveira NLB, Sousa RMC. Diagnóstico de lesões e qualidade de vida de motociclistas, vítimas de acidentes de trânsito. Rev Latinoam Enferm 2003 11:749-56.

4. Marques APP. Reestruturação produtiva e recomposições do trabalho e emprego: um périplo pelas "novas" formas de desigualdade social. Ciênc Saúde Coletiva 2013; 18:1545-54.

5. Salim Filho MT. Políticas públicas e trabalho no transporte alternativo na Amazônia: o moto-táx [Dissertação de Mestrado]. Belém: Programa de Pós-graduação em Desenvolvimento Sustentável do Trópico Úmido, Universidade Federal do Pará; 2007.

6. Silva MB, Oliveira MB, Fontana RT. Atividade do mototaxista: riscos e fragilidades autorreferidos. Rev Bras Enferm 2011; 64:1048-55.

7. Presidência da República. Lei no 12.009, de 29 de julho de 2009. Regulamenta o exercício das atividades dos profissionais em transporte de passageiros, "mototaxista", em entrega de mercadorias e em serviço comunitário de rua, e "motoboy", com o uso de motocicleta. Diário Oficial da União 2009; 30 jul.

8. Conselho Nacional de Trânsito. Resolução no 410, de 2 de agosto de 2012. Regulamenta os cursos especializados obrigatórios destinados a profissionais em transporte de passageiros (mototaxista) e em entrega de mercadorias (motofretista) que exerçam atividades remuneradas na condução de motocicletas e motonetas. http://www.detran. pa.gov.br/menu/mototaxista/resolucao_410.pdf (acessado em 15/Ago/2013).

9. Grisci CLI, Scalco PD, Janovik MS. Modos de trabalhar e de ser de motoboys: a vivência espaçotemporal contemporânea. Psicol Ciênc Prof 2007; 27:446-61.

10. Schlichting C, Cavalheiro EG, Felizari CT. A avaliação da qualidade de vida do profissional motociclista através do método WHOQOL-Bref. Revista Eletrônica da Faculdade Evangélica do Paraná 2012; 2:22-42.

11. Presidência da República. Decreto-Lei no 5.452 , de 1 o de maio de 1943. Aprova a Consolidação das Leis do Trabalho. Diário Oficial da República Federativa do Brasil 1943; 9 ago.

12. The World Health Organization quality of life as sessment (WHOQOL): development and general psychometric properties. Soc Sci Med 1998; 46:1569-85.

13. Fleck MPA, Leal OF, Louzada S, Xavier M, Chachamovich E, Vieira G, et al. Desenvolvimento da versão em português do instrumento de avaliação de qualidade de vida da OMS (WHOQOL-100). Rev Bras Psiquiatr 1999; 21:19-28.

14. International Labour Office. Psychosocial factors at work: recognition and control. Geneva: International Labour Office; 1986.
15. Fernandes MH, Rocha VM. Impact of the psychosocial aspects of work on the quality of life of teachers. Rev Bras Psiquiatr 2009; 31:15-20.

16. Kish L. Survey sampling. New York: Wiley; 1965.

17. Flausino TC. Qualidade de vida e condições de trabalho dos carteiros de Goiânia - Goiás [Dissertação de Mestrado]. Goiânia: Programa de Pós-graduação em Ciências Ambientais e Saúde, Pontifícia Universidade Católica de Goiás; 2011.

18. Araújo EM, Costa MCN, Hogan VK, Mota ELA, Araújo TM, Oliveira NF. Race/skin color differentials in potential years of life lost due to external causes. Rev Saúde Pública 2009; 43:405-12.

19. Fleck MPA, Louzada S, Xavier M, Chamovich E, Vieira G, Santos L, et al. Aplicação da versão em português do instrumento abreviado de avaliação da qualidade de vida “WHOQOL-Bref”. Rev Saúde Pública 2000; 34:178-83.

20. Araújo TM, Karasek R. Validity and reliability of the job content questionnaire in formal and informal jobs in Brazil. Scand J Work Environ Health 2008; 6:52-9.

21. Karasek RA. Job demand, job decision latitude, and mental strain: implications for job redesign. Adm Sci Q 1979; 24:285-308.

22. Araújo TM, Graça CC, Araújo E. Estresse ocupacional e saúde: contribuições do modelo demandacontrole. Ciênc Saúde Coletiva 2003; 8:991-1003.

23. Karasek RA. Job content questionnaire and user's guide. Lowell: University of Massachusetts; 1985.

24. Lira SVG. Comportamento preventivo e de risco no trânsito, referido por mototaxistas regulamentados em Fortaleza-CE [Dissertação de Mestrado]. Fortaleza: Programa de Pós-graduação em Saúde Coletiva, Universidade de Fortaleza; 2008.

25. Almeida EG. A mobilidade urbana nos enredos do serviço de mototáxi em Ituiutaba-MG [Dissertação de Mestrado]. Uberlândia: Programa de Pósgraduação em Geografia, Universidade Federal de Uberlândia; 2010.

26. Albuquerque MES, Morais RS, Ximenes JM, Moura CCB, Freitas Júnior RO, Ximenes Neto FRG. Qualidade de vida no trabalho e riscos ocupacionais dos mototaxistas: um estudo de caso. Revista CPAQV 2012; 4:1-9.

27. Timóteo AGV. A luta diária dos mototaxistas em Campina Grande-PB. Iluminuras 2013; 14:184-95.

28. Almeida EG, Ferreira WR. A entrevista enquanto diálogo assimétrico na geografia dos transportes: uma reflexão sobre o mototaxismo em Ituiutaba. In: Ramires JC, Pessoa VLS, organizadores. Geografia e pesquisa qualitativa. Uberlândia: Assis; 2009. p. $75-90$.

29. Amorin CR. Acidentes de trabalho e sintomas osteomusculares entre mototaxistas de Feira de Santana-BA [Dissertação de Mestrado]. Feira de Santana: Programa de Pós-graduação em Saúde Coletiva, Universidade Estadual de Feira de Santana; 2010. 
30. Neves F. Atributos da qualidade de capacete para motociclista: a percepção dos profissionais motofretistas e mototaxistas [Dissertação de Mestrado]. Santa Maria: Programa de Pós-graduação em Engenharia de Produção, Universidade Federal de Santa Maria; 2011.

31. Cooper CL, Marshall J. Occupational sources of stress: a review of the literature relating to coronary heart disease and mental ill health. In: Cooper CL, editor. From stress to wellbeing: the theory and research on occupational stress and wellbeing. London: Palgrave Macmillan; 2013. p. 3-23.

32. Ferreira FF. Fatores de risco em acidentes envolvendo motocicletas em vias urbanas: a percepção dos condutores profissionais [Dissertação de Mestrado]. Porto Alegre: Programa de Pós-graduação em Engenharia de Produção, Universidade Federal do Rio Grande do Sul; 2009.

33. Cabral AS, Costa SJX, Igarashi I. Estudo ergonômico de mototaxistas. Rev Para Med 2012; 26:1-6.

34. Cançado JED, Braga A, Pereira LAA, Arbex MA, Saldiva PHN, Santos UP. Repercussões clínicas da exposição à poluição atmosférica. J Bras Pneumol 2006; 32 Suppl 2:S5-11.

35. Silva LA, Robazzi MLCC, Terra FS. Relation between workplace accidents and the levels of carboxyhemoglobin in motorcycle taxi drivers. Rev Latinoam Enferm 2013; 21:1119-26.
36. Silva DW, Andrade SM, Soares DA, Nunes EFPA, Melchior R. Condições de trabalho e riscos no trânsito urbano na ótica de trabalhadores motociclistas. Physis (Rio J.) 2008; 18:339-60.

37. Melo DJF. A educação e informalidade: a escolaridade dos mototaxistas como fator decisivo para a sua condição de trabalho. Sociologias Plurais 2013; 1:68-85.

38. Alves MGM, Hökerberg YHM, Faerstein E. Trends and diversity in the empirical use of Karasek's demand-control model (job strain): a systematic review. Rev Bras Epidemiol 2013; 16:125-36.

39. Souza SF, Carvalho FM, Araújo TM, Porto LA. Psychosocial factors of work and mental disorders in electricians. Rev Saúde Pública 2010; 44:710-7.

40. Ferreira DKS, Bonfim C, Augusto LGS. Condições de trabalho e morbidade referida de policiais militares, Recife-PE, Brasil. Saúde Soc 2012; 21:9891000.

41. Cardoso JP, Araújo TM, Carvalho FM, Oliveira NF, Reis EJFB. Aspectos psicossociais do trabalho e dor musculoesquelética em professores. Cad Saúde Pública 2011; 27:1498-506.

Recebido em 18/Dez/2013

Versão final reapresentada em 03/Mai/2014

Aprovado em 19/Mai/2014 